\title{
LYTAK1 attenuates proliferation of retinal pigment epithelial cells through TGF- $\beta$-mediated epithelial-mesenchymal transition via the ERK/AKT signaling pathway
}

\author{
ZHEN CHEN $^{1,2}$, NINGHUA NI ${ }^{1,2}$, YAN MEI $^{1}$ and ZHENGRONG YANG ${ }^{2}$ \\ ${ }^{1}$ Department of Ophthalmology and ${ }^{2}$ Research Center of Fundus Disease of Yunnan, \\ The First People's Hospital of Yunnan, Kunming, Yunnan 650032, P.R. China
}

Received December 18, 2016; Accepted June 29, 2017

DOI: $10.3892 /$ etm.2017.5187

\begin{abstract}
Retinal pigment epithelial (RPE) cells have crucial roles in the initiation and development of human ophthalmic diseases. Our previous study suggested that transforming growth factor- $\beta$ (TGF- $\beta$ )-activated kinase 1 (TAK1) is a potential target in the progression and pathogenesis of human proliferative vitreoretinopathy disease. The present study further analyzed the role of TAK1 inhibitor, LYTAK1, in human RPE cells and explored the potential molecular mechanism of LYTAK1-mediated proliferation of human RPE cells. Proliferation of human RPE cells was investigated following treatment with LYTAK1 and knockdown of TGF- $\beta$. TGF- $\beta$-mediated epithelial-mesenchymal transition (EMT) through regulation of the extracellular signal-regulated kinase (ERK)/protein kinase B (AKT) signaling pathway was also explored to analyze the LYTAK1-mediated mechanism of proliferation in human RPE cells. The present results demonstrated that LYTAK1 administration suppressed TAK1 gene and protein expression in human RPE cells. LYTAK1 administration also inhibited proliferation and migration of human RPE cells in vitro. Outcomes indicated that LYTAK1 treatment downregulated expression levels of TGF- $\beta 1$ and EMT markers, including cadherin, fibronectin and $\alpha$-smooth muscle actin in human RPE cells. Notably, results demonstrated that the ERK/AKT signal pathway was blocked by LYTAK1 in human RPE cells. Knockdown of TGF- $\beta$ markedly inhibited phosphorylation and activity of TAK1 and suppressed the LYTAK1-mediated ERK/AKT signaling pathway in RPE
\end{abstract}

Correspondence to: Professor Ninghua Ni or Dr Yan Mei Department of Ophthalmology, The First People's Hospital of Yunnan, 46 Yanchun Road, Kunming, Yunnan 650032, P.R. China E-mail: nininghuaedu@163.com

E-mail: yanmeiedu@163.com

Key words: retinal pigment epithelial, transforming growth factor- $\beta$-activated kinase 1 , LYTAK1, transforming growth factor- $\beta$, epithelial-mesenchymal transition, extracellular signal-regulated kinase/protein kinase B cells, which further canceled inhibition of RPE cell proliferation by LYTAK1. In conclusion, these findings indicated that LYTAK1 may inhibit RPE cell proliferation through the TGF- $\beta$-mediated EMT/ERK/AKT signaling pathway, suggesting that TAK1 may be a potential target for the treatment of RPE diseases.

\section{Introduction}

The degeneration, necrosis and loss of retinal pigment epithelial (RPE) cells may lead to retina and choroid damage, which further results in the occurrence of retinal degeneration diseases and even impaired vision $(1,2)$. RPE has a key role in maintaining the normal function of the retina, particularly the photoreceptor in the optic nerve system $(3,4)$. RPE dysfunction, loss of vision and degradation are associated with various diseases of the retina, such as retinitis pigment and age-related macular degeneration (AMD) (5). In recent years, increasing reports have investigated the role of RPE in cell pyroptosis, death, inflammasome and lipofuscin phototoxicity $(2,6)$.

LYTAK1 is a novel and specific transforming growth factor- $\beta$ (TGF- $\beta$ )-activated kinase 1 (TAK1) inhibitor, which has demonstrated anti-ovarian cancer function by suppressing ovarian cancer growth (7). Research has explored the capacity of LYTAK1 as an agent for targeting the pro-oncogenic TAK1 in human cancer (8). LYTAK1 has been demonstrated to have potential effects against KRAS mutant colorectal cancer (CRC) cells both in vitro and in vivo, which suggested that LYTAK1 may be exploited as a therapy method against CRC with KRAS mutant (9). Recently, research has indicated that TAK1 is involved in the autophagy process in RPE cells, suggesting that aberrant activity of this kinase impairs autophagy and subsequently leads to alterations in the vitality of RPE cells (10). In addition, a study by Dvashi et al (11) demonstrated that inhibition of TAK1 expression accelerated cellular senescence of RPE cells, which elucidated its role in mechanisms underlying RPE cellular senescence induction in the development of dry AMD. Notably, a previous report demonstrated the suppressive effect of LYTAK1 on the proliferation of RPE cells (12).

Previous reports have indicated that the extracellular signal-regulated kinase $(\mathrm{ERK}) /$ protein kinase B (AKT) 
signaling pathway is involved in ophthalmic diseases $(13,14)$. Activation of the E-cadherin-mediated ERK/AKT signaling pathway is associated with cell-cell interaction, which is important for the proliferation of MSCs (15). In a previous study, TGF- $\beta$-stimulated aberrant expression of class III $\beta$-tubulin via the ERK signaling pathway was investigated in cultured RPE cells (16). ERK/AKT phosphorylation has been demonstrated to be involved in the regulation of cell proliferation through anoctamin 6 deficiency, which has a crucial role in $\mathrm{C} 2 \mathrm{C} 12$ myoblast proliferation via regulating the ERK/AKT signaling pathway (17). Furthermore, a study by Chong and Zheng (18) indicated that artemisinin could protect human RPE cells from hydrogen peroxide-induced oxidative damage through activation of the ERK/cyclic adenosine monophosphate response element-binding protein signaling pathway. These reports suggest that the ERK/AKT signaling pathway is involved in the pathological process of RPE.

The purpose of the present study was to investigate the role of LYTAK1 in human RPE cells and explore the potential molecular mechanism of LYTAK1-mediated proliferation of human RPE cells. In the present study, the results demonstrated that LYTAK1 may suppress the expression of TAK1 and TAK1-binding protein 2 in TGF- $\beta$-induced epithelial-mesenchymal transition (EMT) processes in RPE cells. In addition to this, LYTAK1 efficiently inhibited proliferation of RPE cells through regulation of TGF- $\beta$-mediated EMT via the ERK/AKT signal pathway.

\section{Materials and methods}

Cell culture and experimental groups. The ARPE-19 human RPE cell line was obtained from PromoCell $\mathrm{GmbH}$ (Heidelberg, Germany) and cultured in Dulbecco's modified Eagle's medium supplemented with $1 \%$ penicillin/streptomycin sulfate, $1 \%$ L-glutamine and $10 \%$ fetal bovine serum (all from Gibco; Thermo Fisher Scientific, Inc., Waltham, MA, USA) in a humidified atmosphere containing $5 \% \mathrm{CO}_{2}$ at $37^{\circ} \mathrm{C}$. TGF- $\beta 1$ and LYTAK1 were purchased from Sigma-Aldrich (Merck KGaA, Darmstadt, Germany). Cells were treated with TGF- $\beta 1+$ LYTAK1 $(25 \mu \mathrm{M})$ for $48 \mathrm{~h}$ to analyze the effects of TGF- $\beta 1$ and/or LYTAK1 on RPE cells.

Reverse transcription-quantitative polymerase chain reaction (RT-qPCR). The ARPE-19 human RPE cell line was cultured as above. When the cells reached $85 \%$ confluence, the cells were randomly divided into three groups: Control group, TGF- $\beta 1$ treatment group (10 $\mu \mathrm{M}, 48 \mathrm{~h}$ treatment) and TGF- $\beta 1$ $(10 \mu \mathrm{M})+$ LYTAK1 $(25 \mu \mathrm{M})$ treatment group (48 h treatment) at $37^{\circ} \mathrm{C}$. Total RNA was isolated from RPE cells using TRIzol reagent (Invitrogen; Thermo Fisher Scientific, Inc.) and transcribed into cDNA using a Super Script VILO cDNA Synthesis kit (Life Technologies) according to the protocol provided by the manufacturer. All forward and reverse primers were synthesized by Invitrogen (Thermo Fisher Scientific, Inc.) and are indicated in Table I. Thermocycling conditions included 45 amplification cycles, denaturation at $96^{\circ} \mathrm{C}$ for $120 \mathrm{sec}$, primer annealing at $62^{\circ} \mathrm{C}$ for $30 \mathrm{sec}$ with touchdown to $58^{\circ} \mathrm{C}$ for $45 \mathrm{sec}$, and applicant extension at $72^{\circ} \mathrm{C}$ for $60 \mathrm{sec}$ ). Relative mRNA expression changes were calculated by the $2^{-\Delta \Delta \mathrm{Cq}}$ method (19). The results were expressed as the $n$-fold compared to the control.
Western blot analysis. Cells were homogenized in $1 \mathrm{X}$ radioimmunoprecipitation assay buffer and western blotting was performed to analyze the protein expression. Briefly, protein concentrations were examined using a BCA protein assay (Invitrogen; Thermo Fisher Scientific, Inc.) and protein samples $(40 \mu \mathrm{g})$ was separated by $15 \%$ SDS-PAGE. Proteins were transferred into nitrocellulose membranes (Bio-Rad Laboratories, Inc., Hercules, CA, USA) and the primary antibodies used in the immunoblotting assays were TGF- $\beta 1$ (1:1,000, ab66043), ERK (1:2,000, ab54230), AKT (1:2,000, ab8805), cadherin $(1: 1,000$, ab6528), fibronectin $(1: 1,000$, ab2413), $\alpha$-smooth muscle actin ( $\alpha$-SMA; 1:1,000, ab5831; all from Abcam, Shanghai, China) and $\beta$-actin $(1: 2,000$, G8140; United States Biological, Salem, MA, USA) for $12 \mathrm{~h}$ at $4^{\circ} \mathrm{C}$ following blocking with $5 \%$ skimmed milk for $1 \mathrm{~h}$ at $37^{\circ} \mathrm{C}$. Horseradish peroxidase-conjugated $\mathrm{IgG}$ (Bio-Rad Laboratories, Inc.) was used at a 1:5,000 dilution for $2 \mathrm{~h}$ at $37^{\circ} \mathrm{C}$ and detected using a Western Blotting Luminol reagent (sc-2048; Santa Cruz Biotechnology Inc., Dallas, TX, USA).

Cell proliferation assay. RPE cell proliferation was detected using a Cell Counting kit-8 (CCK-8; 96992MSDS; Merck $\mathrm{KGaA}$; Darmstadt, Germany), according to the manufacturer's instructions. Briefly, RPE cells were cultured in 48-well plates at a density of $1 \times 10^{4}$ cells/well in Dulbecco's modified Eagle's medium (DMEM, Invitrogen; Thermo Fisher Scientific, Inc.) supplemented with $5 \%$ fetal bovine serum (Invitrogen; Thermo Fisher Scientific, Inc.) for $24 \mathrm{~h}$ at $37^{\circ} \mathrm{C}$. RPE cells were treated with LYTAK1 $(20 \mu \mathrm{M})$ for $48 \mathrm{~h}$ at $37^{\circ} \mathrm{C}$. Finally, $10 \mu \mathrm{l} \mathrm{CCK}-8$ solution was added to each well and incubated for $2 \mathrm{~h}$ at $37^{\circ} \mathrm{C}$. The results were measured using a microplate reader at $450 \mathrm{~nm}$.

Transfection with small interfering (si)RNA. All siRNA were synthesized by Invitrogen (Thermo Fisher Scientific, Inc.) including siRNA-TGF- $\beta 1$ (Si-TGF- $\beta 1$ sense, 5 '-CCAGAAAUA CAGCAACAAUUU-3' anti-sense, 5'-AUUGUUGCUGUA UUUCUGGUU-3') or siRNA-vector (Si-vector sense, 5'-AAG TCGAGTCGCGTATGCAGGGCCTG-3' anti-sense, 5'-AAC CTGCATACGCGACTCGACC-3'). RPE cells (1X10 ${ }^{6}$ cells) were transfected with 100 pmol Si-TGF- $\beta 1$ targeting TGF- $\beta 1$ (Applied Biosystems; Thermo Fisher Scientific, Inc.) or Si-vector as a control (Applied Biosystems; Thermo Fisher Scientific, Inc.) using a Cell Line Nucleofector kit L (Lonza Group, Ltd., Basel, Switzerland), according to the manufacturer's instructions.

Wound healing assay. The wound healing assay was performed by following the protocol provided in previous literature (20). RPE cells were cultured in DMEM in a 12-well plate and treated with Si-TGF- $\beta 1$ or Si-vector for $48 \mathrm{~h}$ at $37^{\circ} \mathrm{C}$. A wound was created in the cells. After washing with DMEM medium to remove cell debris, the cells were allowed to migrate for $48 \mathrm{~h}$ at $37^{\circ} \mathrm{C}$, followed by observation under a light microscope (BZ-9000; magnification, x40; Keyence Corporation, Osaka, Japan).

Statistical analysis. Data were presented as the mean \pm standard deviation. Statistical differences were analyzed by one-way analysis of variance followed by multiple comparisons performed with post hoc Bonferroni tests. SPSS version 16.0 
Table I. Sequences of primers.

Sequence direction

\begin{tabular}{lll}
\cline { 2 - 3 } Gene name & \multicolumn{1}{c}{ Reverse } & \multicolumn{1}{c}{ Forward } \\
\hline TAK1 & 5'-TCTATTTCACTCACACCAGCCCG-3' & 5'-ATCCAAAGTACCGTTGAGGCTCC-3' \\
Cadherin & 5'-CTCTTGTTGCCGTGATGAGA-3' & 5'-GTTTATAGCCTGGGCACGAA-3' \\
Fibronectin & 5'-AACATTTCTCAGCTATTGGCTT-3' & 5'-CCATTGCAAATCGCTGCCAT-3' \\
$\alpha-$ SMA & 5'-CACCATTCTGCCCAGGAGCA-3' & 5'-TCCTGCTGGTCCTATTGGT-3' \\
ERK & 5'-GCATCACTACACCCGAACAGA'-3' & 5'-CAAGAACGGTCAGCAGGAAT-3' \\
AKT & 5'-TGAGAGAAGCCACGCTGTC-3' & 5'-CGGAGAACAAACTGGATGAA-3' \\
TGF- $\beta$ & 5'-ATCCATGTGTGACCATGAGGAAATG-3' & 5'-TCGGCTAGTTAGGGTACACTTC-3' \\
$\beta$-actin & 5'-CGGAGTCAACGGATTTGGTC-3' & 5'-AGCCTTCTCCATGGTCGTGA-3' \\
\hline
\end{tabular}

TAK1, transforming growth factor- $\beta$-activated kinase 1 ; TGF- $\beta$, transforming growth factor- $\beta$; $\alpha$-SMA, $\alpha$-smooth muscle actin; ERK, extracellular signal-regulated kinase; AKT, protein kinase B.

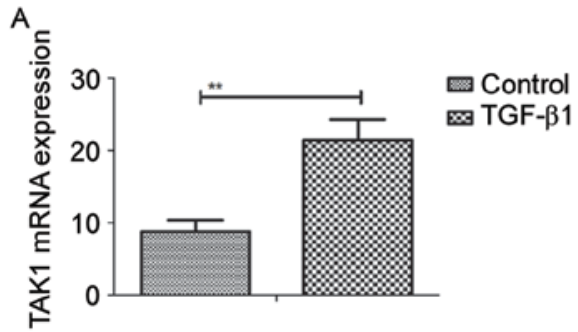

B

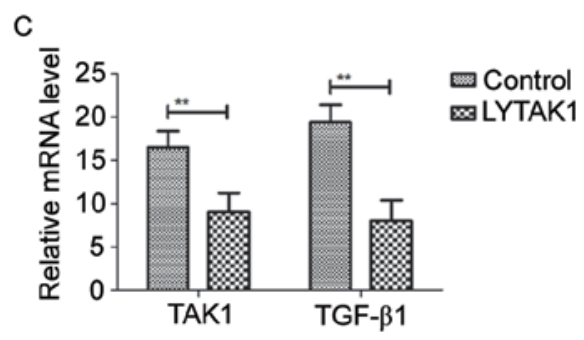

D
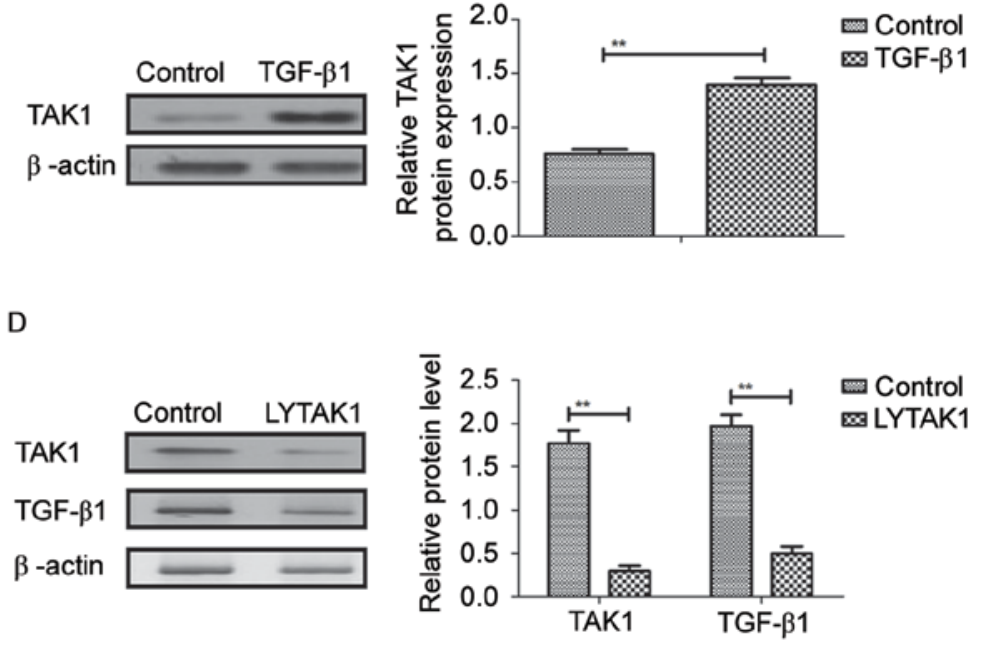

Figure 1. Effects of LYTAK1 on TAK1 expression in TGF- $\beta 1$-induced RPE cells. TGF- $\beta 1$ increases (A) gene and (B) protein expression levels of TAK1 in RPE cells. LYTAK1 downregulates (C) gene and (D) protein expression levels of TAK1 and TGF- $\beta 1$ in RPE cells. ${ }^{* *} \mathrm{P}<0.01$ as indicated. TAK1, transforming growth factor- $\beta$-activated kinase 1 ; LYTAK1, TAK1 inhibitor; RPE, retinal pigment epithelial; TGF- $\beta 1$, transforming growth factor- $\beta 1$.

(SPSS, Inc., Chicago, IL, USA) was used for all statistical analyses. $\mathrm{P}<0.05$ was considered to indicate a statistically significant difference.

\section{Results}

Effects of LYTAK1 on TAK1 expression in TGF- $\beta 1$-induced RPE cells. TAK1 expression was analyzed in TGF- $\beta 1$-induced RPE cells. Results demonstrated that TGF- $\beta 1$ significantly induced TAK1 gene and protein expression in RPE cells compared with the control $(\mathrm{P}<0.01$; Fig. 1A and B). As indicated in Fig. 1C and D, LYTAK1 significantly inhibited gene and protein expression levels of TAK1 and TGF- $\beta 1$ in RPE cells compared with the controls. These results suggested that LYTAK1 inhibited TAK1 expression induced by TGF- $\beta 1$ in RPE cells.

Effects of LYTAK1 on TAK1-binding protein expression in TGF- $\beta$-induced EMT of RPE cells. In order to analyze the effects of LYTAK1 on TGF- $\beta$-induced EMT of RPE cells, expression levels of mesenchymal markers were investigated in the present analysis. It was observed that TGF- $\beta 1$ significantly upregulated mRNA and protein expression levels of cadherin, fibronectin and $\alpha$-SMA in human RPE cells compared with the controls $(\mathrm{P}<0.01$; Fig. $2 \mathrm{~A}$ and $\mathrm{B})$. However, results demonstrated that LYTAK1 administration significantly inhibited mRNA and protein expression levels of cadherin, fibronectin and $\alpha$-SMA in human RPE cells compared with the controls $(\mathrm{P}<0.01$; Fig. $2 \mathrm{C}$ and D). These data suggested that LYTAK1 targeting of TAK1 inhibits TAK1-binding protein expression in TGF- $\beta$-induced EMT of RPE cells.

LYTAK1 ameliorates proliferation of RPE cells and decreases ERK and AKT expression and phosphorylation. As demonstrated in Fig. 3A and B, LYTAK1 had significant inhibitory effects on RPE cell proliferation and migration following treatment for $24 \mathrm{~h}$ compared with the controls 
A

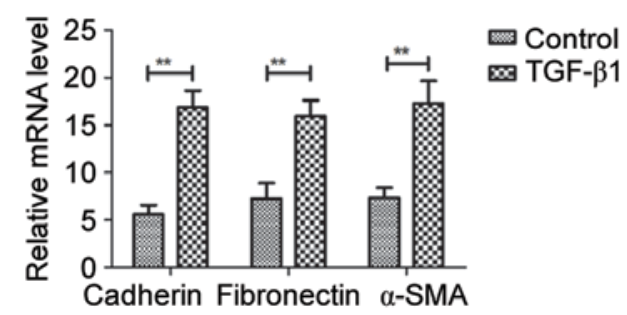

C

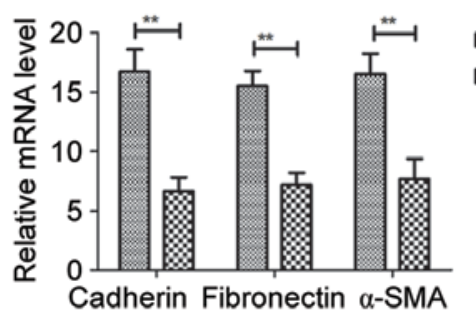

B
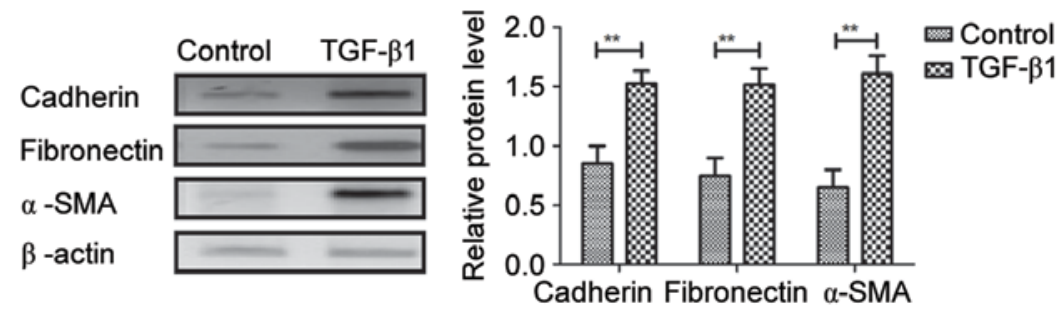

D

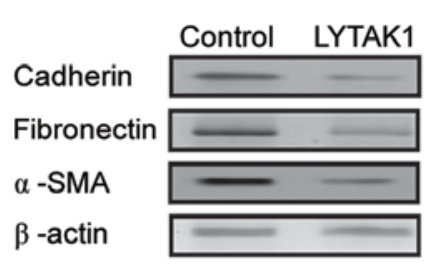

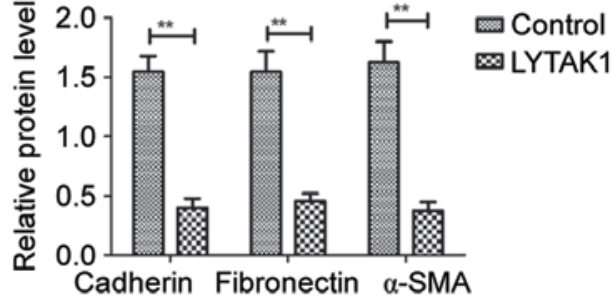

Figure 2. Effects of LYTAK1 on TAK1-binding protein expression in TGF- $\beta$-induced epithelial-mesenchymal transition of RPE cells. TGF- $\beta 1$ upregulated (A) mRNA and (B) protein expression levels of cadherin, fibronectin and $\alpha$-SMA in human RPE cells. LYTAK1 inhibited TGF- $\beta 1$-induced upregulation of (C) mRNA and (D) protein expression levels of cadherin, fibronectin and $\alpha$-SMA in human RPE cells. ${ }^{* *} \mathrm{P}<0.01$ as indicated. TAK1, transforming growth factor- $\beta$-activated kinase 1 ; LYTAK1, TAK1 inhibitor; RPE, retinal pigment epithelial; TGF- $\beta 1$, transforming growth factor- $\beta 1 ; \alpha$-SMA, $\alpha$-smooth muscle actin .

A

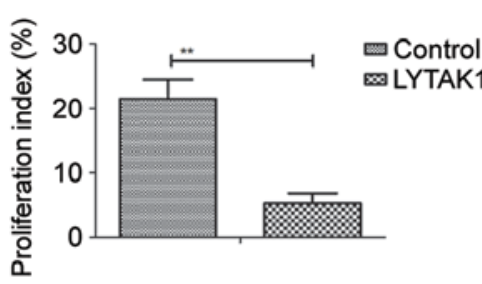

C

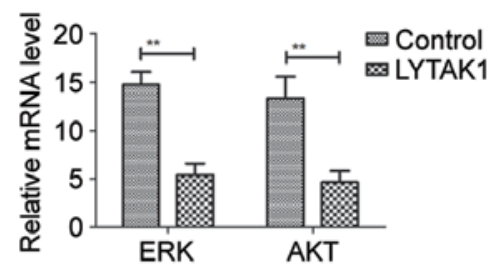

B
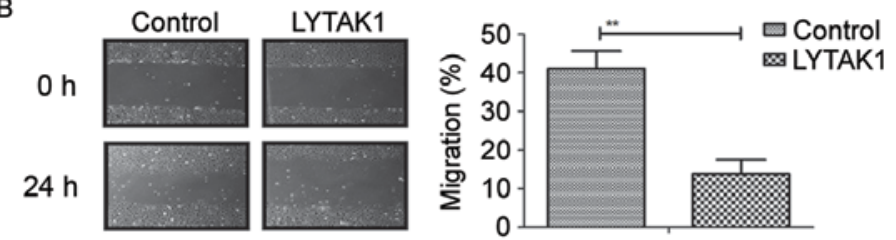

D

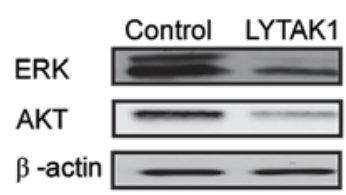

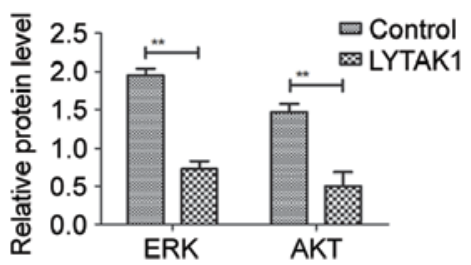

$\mathrm{F}$
E

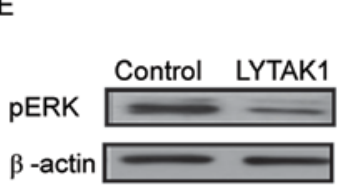

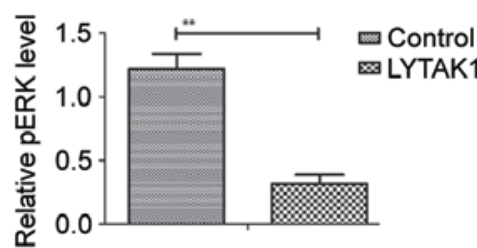
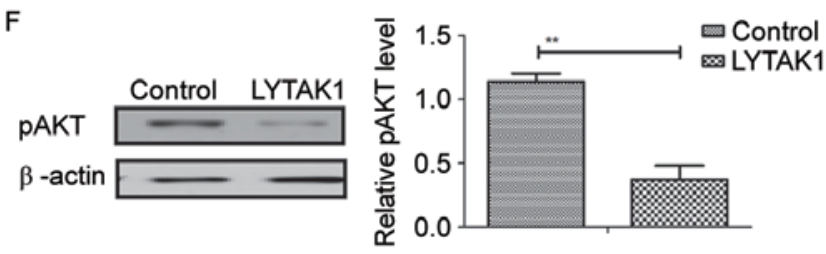

Figure 3. LYTAK1 suppresses proliferation and migration of RPE cells. LYTAK1 inhibited RPE cell (A) proliferation and (B) migration after treatment for $24 \mathrm{~h}$. LYTAK1 administration decreased (C) mRNA and (D) protein expression levels of ERK and AKT in RPE cells. LYTAK1 administration decreased phosphorylation expression levels of (E) ERK and (F) AKT in RPE cells. ${ }^{* * *} \mathrm{P}<0.01$ as indicated. LYTAK1, transforming growth factor- $\beta$-activated kinase 1 inhibitor; RPE, retinal pigment epithelial; ERK, extracellular signal-regulated kinase; AKT, protein kinase B; p, phosphorylated.

$(\mathrm{P}<0.01)$. Results indicated that LYTAK1 administration significantly decreased mRNA and protein expression levels of ERK and AKT in RPE cells compared with the controls $(\mathrm{P}<0.01$; Fig. $3 \mathrm{C}$ and $\mathrm{D})$. Phosphorylation levels of ERK and AKT were significantly downregulated by LYTAK1 in TGF- $\beta$-induced RPE cells compared with controls $(\mathrm{P}<0.01$; Fig. 3E and F). These results suggested that LYTAK1 inhibited the proliferation of RPE cells and decreased ERK and
AKT expression and phosphorylation in TGF- $\beta$-induced EMT of RPE cells.

LYTAK1 regulates proliferation of RPE cells through inhibition of TGF- $\beta$-mediated EMT via the ERK/AKT signaling pathway. In order to analyze the potential mechanism of LYTAK1-inhibited proliferation of RPE cells, the ERK/AKT signaling pathway was investigated in RPE cells. It was 
A
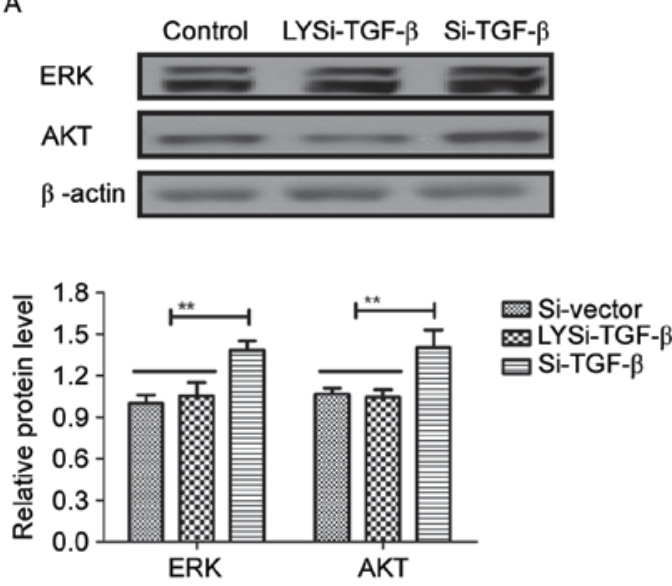

C

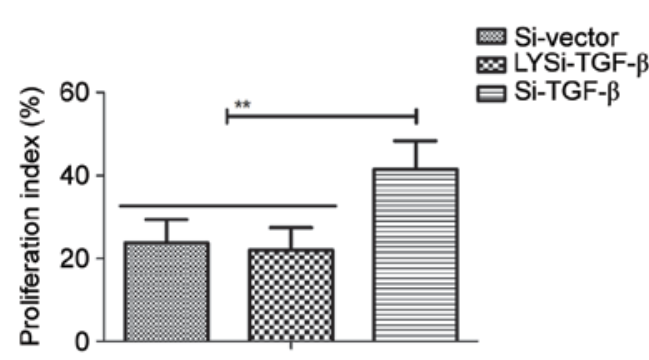

B
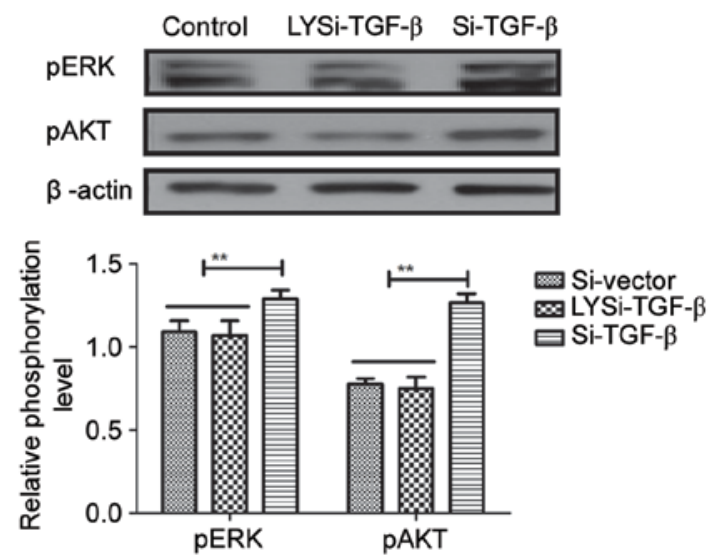

D

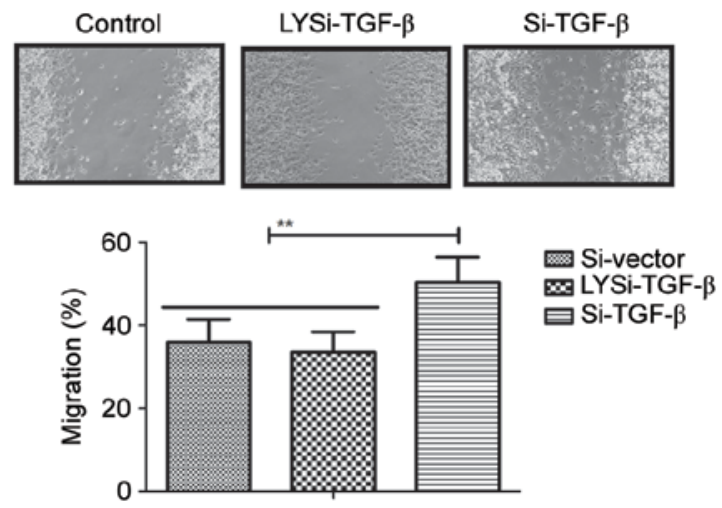

Figure 4. LYTAK1 regulates proliferation of RPE cells through inhibition of TGF- $\beta$-mediated epithelial-mesenchymal transition via the ERK/AKT signaling pathway. Knockdown of TGF- $\beta$ by Si-TGF- $\beta$ blocked LYTAK1-inhibited (A) expression and (B) phosphorylation levels of ERK and AKT in RPE cells. Knockdown of TGF- $\beta$ by Si-TGF- $\beta$ abolished the migration inhibition induced by LYTAK1 (C) proliferation and (D) migration of RPE cells. ${ }^{* *} \mathrm{P}<0.01$ as indicated. LYTAK1, transforming growth factor- $\beta$-activated kinase 1 inhibitor; RPE, retinal pigment epithelial; ERK, extracellular signal-regulated kinase; AKT, protein kinase B; , phosphorylated; TGF- $\beta$, transforming growth factor- $\beta$; Si, small interfering; LYSi-TGF- $\beta$, cells treated with TAK1 inhibitor and Si-TGF- $\beta$.

demonstrated that knockdown of TGF- $\beta$ by Si-TGF- $\beta$ blocked LYTAK1-inhibited expression (LYSi-TGF- $\beta$ ) and phosphorylation levels of ERK and AKT in RPE cells compared with cells transfected with si-TGF- $\beta(\mathrm{P}<0.01$; Fig. $4 \mathrm{~A}$ and $\mathrm{B})$. LYTAK1-inhibited proliferation of RPE cells was also canceled by knockdown of TGF- $\beta$ ( $\mathrm{P}<0.01$; Fig. 4C). Results also demonstrated that knockdown of TGF- $\beta$ abolished the migration inhibition induced by LYTAK1 ( $\mathrm{P}<0.01$; Fig. 4D). These results indicated that LYTAK1 regulated proliferation of RPE cells through inhibition of TGF- $\beta$-mediated EMT via the ERK/AKT signaling pathway.

Knockdown of TGF- $\beta$ inhibits phosphorylation and activity of TAK1 in RPE cells. Effects of TGF- $\beta$ knockdown on phosphorylation and activity of TAK1 in RPE cells were further analyzed in RPE cells. As demonstrated in Fig. 5A, expression and phosphorylation levels of TAK1 were significantly decreased by Si-TGF- $\beta$ and Si-TGF- $\beta$ abolished the inhibition induced by LYTAK1 in RPE cells $(\mathrm{P}<0.01)$. Activity of TAK1 in RPE cells mediated by LYTAK1 was also significantly abolished by Si-TGF- $\beta$ in RPE cells $(\mathrm{P}<0.01$; Fig. 5B). LYTAK1 downregulation of mRNA and protein expression levels of cadherin, fibronectin and $\alpha$-SMA were significantly inhibited by TGF- $\beta$ knockdown in human RPE cells $(\mathrm{P}<0.01$; Fig. 5C and D). These results suggested that knockdown of
TGF- $\beta$ inhibited phosphorylation and activity of TAK1 in RPE cells.

\section{Discussion}

Currently, proliferation and migration of RPE cells has an essential role in the progression of proliferative vitreoretinopathy (PVR) and other fibro-proliferative eye diseases $(21,22)$. Evidence has indicated that viability of RPE cells is associated with various ophthalmic diseases through regulation of EMT molecular markers (22). Research has also demonstrated that RPE cell apoptosis is influenced by a combination of macrophages and soluble mediators in the progression of AMD (11). Additionally, our previous study suggested that TAK1 inhibitor could suppress proliferation and EMT in RPE cells (12). In the present study, the molecular mechanism of TAK1 inhibitor (LYTAK1) was further explored in EMT of RPE cells. The present results indicated that LYTAK1 administration suppressed TAK1 gene and protein expression in human RPE cells, which further inhibited proliferation and migration of human RPE cells in vitro. The dose of LYTAK1 used in the present study has no toxicity to RPE cultured cells as the total ERK and AKT proteins were downregulated in cultured RPE cells. Notably, the findings indicated that LYTAK1 inhibited RPE cell proliferation mediated by the TGF- $\beta$-mediated 
A
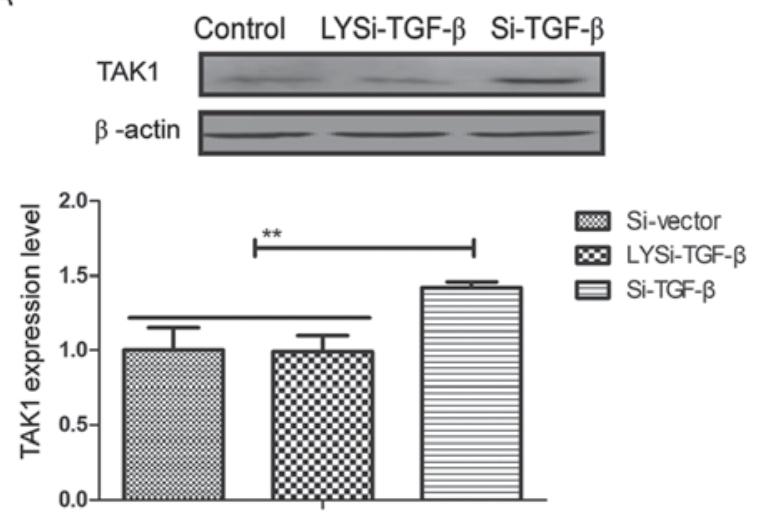

C

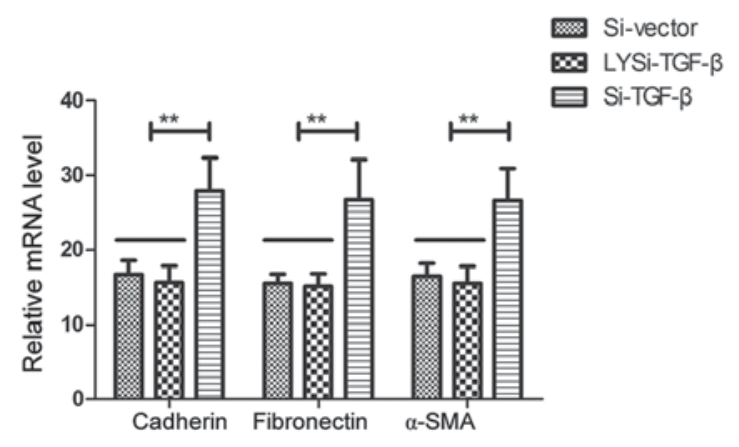

B

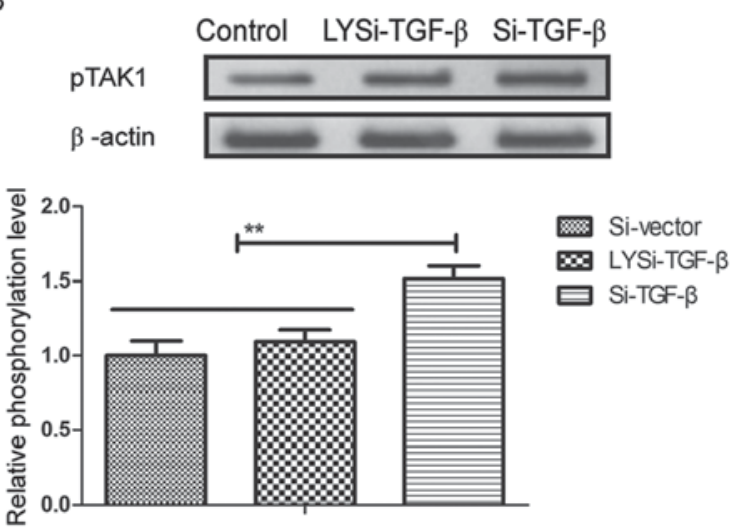

D

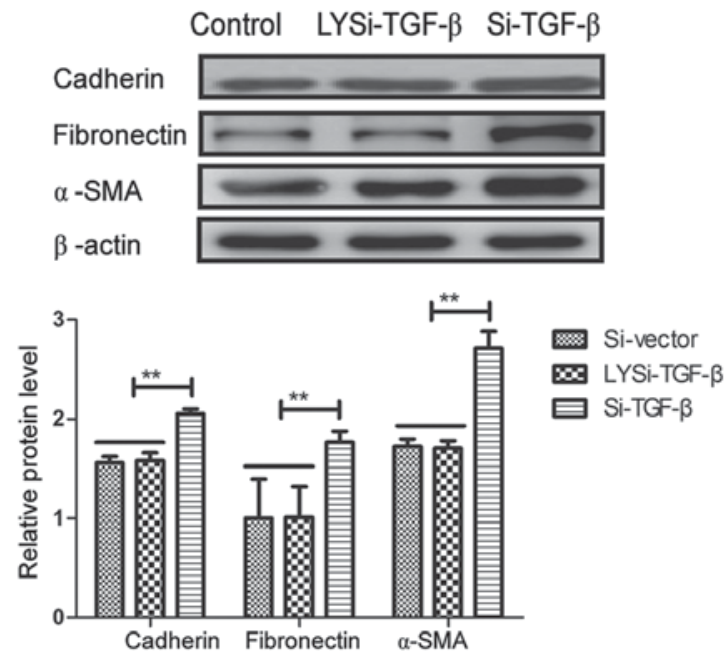

Figure 5. Knockdown of TGF- $\beta$ inhibits phosphorylation and activity of TAK1 in RPE cells. (A) Expression and (B) phosphorylation levels of TAK1 were significantly decreased by Si-TGF- $\beta$ and Si-TGF- $\beta$ abolished the inhibition induced by LYTAK1 in RPE cells. Knockdown of TGF- $\beta$ inhibited activity of TAK1 in RPE cells. Si-TGF- $\beta$ upregulated (C) mRNA and (D) protein expression levels of cadherin, fibronectin and $\alpha-S M A$ in human RPE cells. ${ }^{* *}$ P $<0.01$ as indicated. TGF- $\beta$, transforming growth factor- $\beta$; TAK1, transforming growth factor- $\beta$-activated kinase 1 ; RPE, retinal pigment epithelial; Si, small interfering; LYSi-TGF- $\beta$, cells treated with TAK1 inhibitor and Si-TGF- $\beta$; $p$, phosphorylated; $\alpha$-SMA, $\alpha$-smooth muscle actin.

EMT/ERK/AKT signaling pathway, suggesting that TAK1 is a potential target for the treatment of RPE diseases.

Activity of RPE cells is involved in the pathogenesis of PVR, which derives from EMT and further leads to proliferation and migration of RPE cells $(23,24)$. The pathological significance of the EMT process in the progression of PVR is becoming increasingly recognized. A study by Sheridan et al (25) indicated that migration of RPE cells is related to the pathology of PVR by regulation of matricellular proteins, thrombospondin-1 and osteonectin. In addition, research has suggested that proliferation and migration of RPE-derived cells contributes to in taut subretinal strands from patients with PVR (26). Furthermore, inhibition of DNA methylation and methyl-CGP-binding protein 2 suppresses RPE transdifferentiation, which further leads to PVR (27). The results of the present study demonstrated that LYTAK1 downregulated TGF- $\beta 1$ expression levels and cadherin, fibronectin and $\alpha$-SMA in EMT of human RPE cells, which further resulted in inhibition of RPE cell proliferation.

Previous research has indicated that TGF- $\beta$ overexpression aggravates the proliferation and is associated with apoptosis of RPE cells in vitro (28). A study by Alge-Priglinger et al (29) suggested that negative regulation of RPE cell attachment by carbohydrate-dependent cell surface galectin-3 protein by inhibition of the ERK-mitogen-activated protein kinase pathway disclosed a promising nouveau perspective for treatment and prophylaxis of early PVR. Research has also suggested that inhibition of the phosphoinositide 3-kinase/AKT and MEK/ERK signaling pathways suppresses proliferation, migration and collagen I mRNA expression in human RPE cells (30). Additionally, regulation of AKT pathways inhibits the migration of RPE cells, which further contributes to the improvement of PVR (31-33). In the present study, results demonstrated that the ERK/AKT signaling pathway was blocked by LYTAK1 in human RPE cells. Furthermore, results indicated that LYTAK1 regulated proliferation of RPE cells through inhibition of TGF- $\beta$-mediated EMT via the ERK/AKT signaling pathway, while knockdown of TGF- $\beta$ inhibited phosphorylation and activity of TAK1 and decreased migration of RPE cells inhibited by LYTAK1.

In conclusion, the present study identified the role of TAK1 inhibitor in TGF- $\beta 1$-induced EMT in human RPE cells. Findings suggested that LYTAK1 not only inhibited TAK1 expression and TAK1-binding protein expression induced by TGF- $\beta 1$, but also decreased ERK and AKT expression and phosphorylation in RPE cells. Notably, the underlying 
mechanism of LYTAK1 affects TGF- $\beta$-mediated EMT via the ERK/AKT signaling pathway in RPE cells. Therefore, the present results suggest that inhibition of TAK1 activity may be promising for the treatment of PVR.

\section{Acknowledgements}

This study was supported by the Health Science and Technology Projects of Yunnan Province (grant no. 2016NS239) and the Yunnan Applied Basic Research Projects-Union Foundation [grant no. 2017FE468(-119)].

\section{References}

1. Devarajan G, Niven J, Forrester JV and Crane IJ: Retinal pigment epithelial cell apoptosis is influenced by a combination of macrophages and soluble mediators present in age-related macular degeneration. Curr Eye Res 41: 1235-1244, 2016.

2. Chen M, Rajapakse D, Fraczek M, Luo C, Forrester JV and Xu H: Retinal pigment epithelial cell multinucleation in the aging eye-a mechanism to repair damage and maintain homoeostasis. Aging Cell 15: 436-445, 2016.

3. Joshi R, Mankowski W, Winter M, Saini JS, Blenkinsop TA, Stern JH, Temple S and Cohen AR: Automated measurement of cobblestone morphology for characterizing stem cell derived retinal pigment epithelial cell cultures. J Ocul Pharmacol Ther 32: 331-339, 2016.

4. Hanus J, Anderson C, Sarraf D, Ma J and Wang S: Retinal pigment epithelial cell necroptosis in response to sodium iodate. Cell Death Discov 2: 16054, 2016.

5. Lee GY, Kang SJ, Lee SJ, Song JE, Joo CK, Lee D and Khang G: Effects of small intestinal submucosa content on the adhesion and proliferation of retinal pigment epithelial cells on SIS-PLGA films. J Tissue Eng Regen Med 11: 99-108, 2017.

6. Brandstetter C, Patt J, Holz FG and Krohne TU: Inflammasome priming increases retinal pigment epithelial cell susceptibility to lipofuscin phototoxicity by changing the cell death mechanism from apoptosis to pyroptosis. J Photochem Photobiol B 161: 177-183, 2016.

7. Ying L, Chunxia Y and Wei L: Inhibition of ovarian cancer cell growth by a novel TAK1 inhibitor LYTAK1. Cancer Chemother Pharmacol 76: 641-650, 2015.

8. Sakurai H: Targeting of TAK1 in inflammatory disorders and cancer. Trends Pharmacol Sci 33: 522-530, 2012.

9. Zhou J, Zheng B, Ji J, Shen F, Min H, Liu B, Wu J and Zhang S: LYTAK1, a novel TAK1 inhibitor, suppresses KRAS mutant colorectal cancer cell growth in vitro and in vivo. Tumour Biol 36: 3301-3308, 2015.

10. Green YA, Ben-Yaakov K, Adir O, Pollack A and Dvashi Z: TAK1 is involved in the autophagy process in retinal pigment epithelial cells. Biochem Cell Biol 94: 188-196, 2016.

11. Dvashi Z, Green Y and Pollack A: TAK1 inhibition accelerates cellular senescence of retinal pigment epithelial cells. Invest Ophthalmol Vis Sci 55: 5679-5686, 2014.

12. Chen Z, Mei Y, Lei H, Tian R, Ni N, Han F, Gan S and Sun S: LYTAK1, a TAK1 inhibitor, suppresses proliferation and epithelialmesenchymal transition in retinal pigment epithelium cells. Mol Med Rep 14: 145-150, 2016.

13. Chou WW, Chen KC, Wang YS, Wang JY, Liang CL and Juo SH: The role of SIRT1/AKT/ERK pathway in ultraviolet B induced damage on human retinal pigment epithelial cells. Toxicol In Vitro 27: 1728-1736, 2013.

14. Jiang Q, Cao C, Lu S, Kivlin R, Wallin B, Chu W, Bi Z, Wang X and Wan Y: MEK/ERK pathway mediates UVB-induced AQP1 downregulation and water permeability impairment in human retinal pigment epithelial cells. Int J Mol Med 23: 771-777, 2009

15. Lee EJ, Park SJ, Kang SK, Kim GH, Kang HJ, Lee SW, Jeon HB and Kim HS: Spherical bullet formation via E-cadherin promotes therapeutic potency of mesenchymal stem cells derived from human umbilical cord blood for myocardial infarction. Mol Ther 20: 1424-1433, 2012.
16. Chung EJ, Chun JN, Jung SA, Cho JW and Lee JH: TGF- $\beta$ stimulated aberrant expression of class III $\beta$-tubulin via the ERK signaling pathway in cultured retinal pigment epithelial cells. Biochem Biophys Res Commun 415: 367-372, 2011.

17. Zhao P, Torcaso A, Mariano A, Xu L, Mohsin S, Zhao L and Han R: Anoctamin 6 regulates $\mathrm{C} 2 \mathrm{C} 12$ myoblast proliferation. PLoS One 9: e92749, 2014.

18. Chong CM and Zheng W: Artemisinin protects human retinal pigment epithelial cells from hydrogen peroxide-induced oxidative damage through activation of ERK/CREB signaling. Redox Biol 9: 50-56, 2016.

19. Livak KJ and Schmittgen TD: Analysis of relative gene expression data using real-time quantitative PCR and the 2(-Delta Delta C(T)) method. Methods 25: 402-408, 2001

20. Stamp ME, Brugger MS, Wixforth A and Westerhausen C: Acoustotaxis -in vitro stimulation in a wound healing assay employing surface acoustic waves. Biomater Sci 4: 1092-1099, 2016.

21. Kwon OW, Song JH and Roh MI: Retinal Detachment and Proliferative Vitreoretinopathy. Dev Ophthalmol 55: 154-162, 2016.

22. Lai FH, Lo EC, Chan VC, Brelen M, Lo WL and Young AL: Combined pars plana vitrectomy-scleral buckle versus pars plana vitrectomy for proliferative vitreoretinopathy. Int Ophthalmol 36: 217-224, 2016.

23. García S, López E and López-Colomé AM: Glutamate accelerates RPE cell proliferation through ERK1/2 activation via distinct receptor-specific mechanisms. J Cell Biochem 104: 377-390, 2008.

24. Palma-Nicolás JP, López E and López-Colomé AM: Thrombin stimulates RPE cell motility by PKC-zeta- and NF-kappaBdependent gene expression of MCP-1 and CINC-1/GRO chemokines. J Cell Biochem 110: 948-967, 2010.

25. Sheridan CM, Magee RM, Hiscott PS, Hagan S, Wong DH, McGalliard JN and Grierson I: The role of matricellular proteins thrombospondin-1 and osteonectin during RPE cell migration in proliferative vitreoretinopathy. Curr Eye Res 25: 279-285, 2002.

26. Winkler $\mathrm{J}$ and Hoerauf H: TGF- $\beta$ and RPE-derived cells in taut subretinal strands from patients with proliferative vitreoretinopathy. Eur J Ophthalmol 21: 422-426, 2011

27. He S, Barron E, Ishikawa K, Nazari Khanamiri H, Spee C, Zhou P, Kase S, Wang Z, Dustin LD and Hinton DR: Inhibition of DNA methylation and methyl-CpG-binding protein 2 suppresses RPE transdifferentiation: Relevance to proliferative vitreoretinopathy. Invest Ophthalmol Vis Sci 56: 5579-5589, 2015.

28. Enzmann V, Hollborn M, Wiedemann P and Kohen L: Minor influence of the immunosuppressive cytokines IL-10 and TGF-beta on the proliferation and apoptosis of human retinal pigment epithelial (RPE) cells in vitro. Ocular Immunol Inflamm 9: 259-266, 2001.

29. Alge-Priglinger CS, André S, Schoeffl H, Kampik A, Strauss RW, Kernt M, Gabius HJ and Priglinger SG: Negative regulation of RPE cell attachment by carbohydrate-dependent cell surface binding of galectin-3 and inhibition of the ERK-MAPK pathway. Biochimie 93: 477-488, 2011.

30. Qin D, Zheng XX and Jiang YR: Apelin-13 induces proliferation, migration, and collagen I mRNA expression in human RPE cells via PI3K/Akt and MEK/Erk signaling pathways. Mol Vis 19: 2227-2236, 2013

31. Tang B, Cai J, Sun L, Li Y, Qu J, Snider BJ and Wu S: Proteasome inhibitors activate autophagy involving inhibition of PI3K-AktmTOR pathway as an anti-oxidation defense in human RPE cells. PLoS One 9: e103364, 2014.

32. Bulloj A, Duan W and Finnemann SC: PI 3-kinase independent role for AKT in F-actin regulation during outer segment phagocytosis by RPE cells. Exp Eye Res 113: 9-18, 2013.

33. Cheung YH, Sheridan CM, Lo AC and Lai WW: Lectin from Agaricus bisporus inhibited $S$ phase cell population and Akt phosphorylation in human RPE cells. Invest Ophthalmol Vis Sci 53: 7469-7475, 2012. 